\title{
The Incorporation of Acetate and Palmitate into Lipids by Human Platelets
}

\author{
Daniel Deykin and Richard K. Desser \\ with the technical assistance of Carole R. PrItzker, \\ Chekwa Okigwe, and Carole J. Wittkopf
}

From the Department of Medicine, Beth Israel Hospital and Harvard

Medical School, Boston, Massachusetts 02115

A в S T RACT The optimal conditions for the incorporation of acetate- $1-{ }^{14} \mathrm{C}$ and palmitic acid- $1-{ }^{14} \mathrm{C}$ into platelet lipids have been described. In buffer incubations with acetate there was a sharp $\mathrm{pH}$ optimum at 6.8 ; in plasma incubations, there was a broad $\mathrm{pH}$ optimum between 6.8-7.4. Maximal incorporation of acetate occurred at a final concentration of 1.5 mmoles/liter. In buffer, no labeled lipids were released from platelets into the medium. In plasma, $40 \%$ of newly formed lipids was recovered in the plasma. $75 \%$ of the incorporated acetate could be recovered in ceramide, lecithin, and free fatty acids. Platelet fatty acids were formed both by de novo synthesis and chain elongation. The fatty acids formed by de novo synthesis exchanged with plasma free fatty acids. In buffer incubations no turnover of newly labeled lipids occurred, but in the plasma incubations exchange of newly labeled lecithin with plasma lipids was demonstrable. Palmitic acid-1-14 $\mathrm{C}$ added to plasma was incorporated into platelet lipids. The distribution among the lipid classes of palmitate taken up from plasma was the same as that of palmitate formed intracellularly by de novo synthesis.

\section{INTRODUCTION}

The incorporation of acetate into lipids by the formed elements of the blood has been well documented (1-7). The optimal acetate concentration for lipid synthesis (1), the distribution of labeled lipids among the various lipid classes $(1,2)$, and

Received for publication 6 November 1967 and in revised form 16 February 1968. the pattern of labeling of individual fatty acids (2) have been extensively studied in white cells. Similarly, the uptake of palmitate by white cells has been reported $(3,4)$. Mature red cells are incapable of incorporating acetate into long-chain fatty acids, and this defect has been shown to be due to the lack of acetyl CoA carboxylase in the mature erythrocyte (5). The red cell can take up preformed palmitate from a complex with albu$\min (4)$.

Much less is known of the incorporation of acetate or palmitate into platelet lipids. It has been established that platelets incorporate acetate into the major lipid classes $(1,6)$, that both de novo and chain elongation pathways of fatty acid synthesis are operative in the platelet (7), and that platelets release lipids into plasma (1). It is also known that platelets can take up and oxidize palmitate from an albumin-bound complex (4).

In the present study the optimal conditions for the incorporation of acetate- $1{ }^{14} \mathrm{C}$ into platelet lipids have been characterized. The distribution of newly incorporated acetate among lipid classes has been reexamined, and it has been shown that $75 \%$ of the acetate can be recovered in three lipid classes: $(a)$ the neutral sphingolipid, ceramide; (b) lecithin; and (c) free fatty acids. We have confirmed the synthesis of platelet fatty acids by both the de novo pathway and by chain elongation, and we have shown in addition that the fatty acids formed by de novo synthesis exchange with plasma free fatty acids. Our data demonstrate that platelets incorporate palmitic acid into complex lipids; the distribution among the lipid classes of palmitate 
taken up from plasma is the same as that of palmitate formed intracellularly by de novo synthesis.

\section{METHODS}

A. Preparation of platelets. Platelets were collected from normal donors, using the acid-citrate anticoagulant of Aster and Jandl (8). All glassware and blood-drawing equipment were siliconized (Siliclad, Clay-Adams, Inc., New York). Platelet-rich plasma was prepared by centrifugation at $275 \mathrm{~g}$ for $15 \mathrm{~min}$ at $23^{\circ} \mathrm{C}$. Platelet pellets were obtained by further centrifugation at $2500 \mathrm{~g}$ for 5 $\min$ at $4^{\circ} \mathrm{C}$. The platelets were resuspended at $4^{\circ} \mathrm{C}$ with a Pasteur pipette in Gaintner's phosphate buffer (9), modified, in that the $\mathrm{pH}$ of the buffer was 6.5 and that ethylenediaminetetraacetate (EDTA) was omitted. The platelets were washed twice at $4^{\circ} \mathrm{C}$ in the same buffer and were finally resuspended in the buffer at a final concentration of approximately $1 \times 10^{\circ}$ platelets $/ \mathrm{ml}$. The platelets remained evenly suspended for at least $4 \mathrm{hr}$ at $4^{\circ} \mathrm{C}$ and maintained their ability to aggregate in response to adenosine diphosphate in the presence of plasma (10). Examination of stained smears of platelet pellets and direct enumeration of cells in the final suspension revealed the preparation to be free from white cell contamination.

B. Lipid preparations. Acetate-1- ${ }^{14} \mathrm{C}$ was purchased from New England Nuclear Corp., Boston, Mass. The specific activity of the acetate was varied, from between 2 to $50 \mathrm{mc} / \mathrm{mmole}$, as determined by the needs of individual experiments by the addition of unlabeled sodium acetate. The radiopurity of the acetate $-1-{ }^{14} \mathrm{C}$ was determined for each lot by ascending paper chromatography in two solvent systems. The radiopurity was routinely greater than $99 \%$. Palmitic acid- $1{ }^{14} \mathrm{C}$ was purchased from New England Nuclear Corporation. Gas-liquid chromatography revealed $97 \%$ of the radioactivity to be palmitic acid. Mono-olein- $1-{ }^{14} \mathrm{C}$ was the gift of Dr. Alan Hoffman, Mayo Clinic, Rochester, Minn.

Nonradioactive lipids were purchased from Applied Science Corp., State College, Pa., 1- and 2-mono-olein were the gift of Dr. Fred Mattson, Proctor and Gamble Co., Cincinnati, Ohio. Dipalmitoyl phosphatidic acid, dipalmitin, and beef heart cardiolipin were the gift of Dr. James Carter, Department of Medicine, Massachusetts General Hospital, Boston, Mass. Ceramide and cerebroside preparations were obtained commercially (Applied Sciences Corp.) and were the gift of Dr. Peter Schneider, Department of Medicine, Beth Israel Hospital, Boston, Mass. Organic solvents were of reagent grade and were redistilled before use. The purity of all nonradioactive lipids was established by thin-layer chromatography.

C. Incubation technics. Incubations were conduced in siliconized 25-ml Erlenmeyer flasks placed in a metabolic incubator at $37^{\circ} \mathrm{C}$ under an atmosphere of $95 \% \quad \mathrm{O}_{2}$ and $5 \% \mathrm{CO}_{2}$. To $1 \mathrm{ml}$ of the platelet suspension we added $1.0 \mathrm{ml}$ of either phosphate buffer or human plasma which was dialyzed extensively against $(5 \mathrm{ml}$ vs. 6 liters of buffer per $8 \mathrm{hr}$ ) the same buffer. The $\mathrm{pH}$ of the platelet suspension, the phosphate buffer, and the dialyzed plasma were adjusted to $\mathrm{pH} 6.8$ with $0.1 \mathrm{~N} \mathrm{NaOH}$ before combination. Control experiments indicated that the $\mathrm{pH}$ of the mixture was also 6.8 , and it remained stable during the incubation. The reaction was initiated by the addition of sodium acetate- $1{ }^{11} \mathrm{C}$ in $100 \mu \mathrm{l}$ of distilled water. The final volume of the incubation mixture was $2.2 \mathrm{ml}$, which contained phosphate buffer ( $\mathrm{pH} 6.8$ ), $90 \mu$ moles; potassium, $9 \mu$ moles ; sodium, $285 \mu$ moles ; chloride, $210 \mu$ moles ; glucose, $2.0 \mathrm{mg}$; and acetate $5.5 \mu$ moles. In certain experiments the $\mathrm{pH}$ was varied; in others, the concentration of acetate was altered. The reaction was terminated by transferring the contents of the incubation flask to iced centrifuge tubes. The platelets were separated from the incubation medium immediately by centrifugation at $2500 \mathrm{~g}$ for $10 \mathrm{~min}$ at $4^{\circ} \mathrm{C}$. Direct platelet counts revealed no disruption of cells during incubation (within the $5 \%$ error of the counting technic). The medium (either plasma or buffer) was removed from the platelet pellet and the platelets were washed twice in phosphate buffer, $\mathrm{pH}$ 6.5. In experiments in which the time-course of incorporation of acetate into lipids was studied, $500 \mu$ moles of unlabeled acetate was added to terminate the reaction, and the platelets and medium were separated as in other experiments.

Palmitic acid-1 ${ }^{14} \mathrm{C}$ was complexed to plasma albumin by dissolving the acid (SA $5 \mathrm{mc} / \mathrm{mmole}$ ) in acetone at a final concentration of $50 \mu \mathrm{c} / \mathrm{ml} .100 \mu \mathrm{l}$ of the acetone solution $(5 \mu \mathrm{c})$ was added with constant swirling under the surface of $1 \mathrm{ml}$ of plasma warmed to $37^{\circ} \mathrm{C}$. The acetone was then driven off by incubating at $37^{\circ} \mathrm{C}$ under a stream of nitrogen.

Incubations with palmitic acid were conducted by addition of $1 \mathrm{ml}$ of platelet suspension to $1 \mathrm{ml}$ of the plasma containing the palmitic acid-1 ${ }^{14} \mathrm{C}$. Reactions were terminated by separating the platelets by centrifugation. The platelets were washed five times in a solution of Gaintner's buffer and dialyzed plasma $(1: 1, \mathrm{v} / \mathrm{v})$ to remove unreacted and dissociable palmitic acid-1- ${ }^{14} \mathrm{C}$ before extraction of platelet lipids.

D. Extraction of lipids. The lipids were extracted from platelets and incubation media by a modified Folch procedure (11). The washed platelet suspension and incubation media were transferred separately to $50 \mathrm{ml}$ of chloroform: methanol $(2: 1 \mathrm{v} / \mathrm{v})$, which previously had been freed from oxygen by extensive exposure to bubbling nitrogen. Lipids were allowed to extract for $30 \mathrm{~min}$, whereupon $10 \mathrm{ml}$ of isotonic saline was added and the mixture was vigorously shaken which resulted in a twophase system. The lower chloroform phase was clarified by centrifugation at $1000 \mathrm{~g}$ for $10 \mathrm{~min}$ and the upper phase containing unreacted free acetate and water soluble components was drawn off. The lower chloroform phase was then washed three additional times with $10 \mathrm{ml}$ of isotonic saline. The chloroform phase was concentrated for further analysis by evaporation at reduced temperature in vacuo. Control experiments were conducted in which $10 \mu \mathrm{c}$ of acetate- $1-{ }^{14} \mathrm{C}$ (SA $2 \mu \mathrm{c} / \mu$ mole) was added to platelets suspended in either plasma or buffer at $0^{\circ} \mathrm{C}$. The contents of the flasks were immediately extracted and the chloroform phase was washed as described above. 
The chloroform phases contained less than $150 \mathrm{cpm}$. Therefore, there was minimal contamination of the chloroform with unreacted acetate.

E. Thin-layer chromatography. Thin-layer chromatography was conducted with Silica Gel H (Brinkmann Instruments, Inc., Westbury, L. I., N. Y.), prepared by adding $83 \mathrm{ml}$ of distilled water to $30 \mathrm{~g}$ of gel. The slurry was prepared by mixing in a Waring Blendor for 60 sec. It was applied at a thickness of $0.250 \mathrm{~mm}$. Plates were air-dried $60 \mathrm{~min}$, activated at $110^{\circ} \mathrm{C}$ for $1 \mathrm{hr}$, and allowed to cool in a dessicator for use within $30 \mathrm{~min}$. In some instances chromatography was performed on silicic acid-impregnated paper (No. S 681 Whatman filter paper, H. Reeve \& Angel Co., Inc., Clifton, N. J.). All samples were applied under a nitrogen atmosphere. Routinely, carrier cholesterol, palmitic acid, mono-olein, di-olein, tripalmitin, and cholesteryl palmitate $(50 \mu \mathrm{g}$ each) were added to platelet lipid extracts to make visible neutral lipids. No carrier was added to plasmacontaining incubation medium extracts. The silica gel plates and silicic acid papers were developed in sealed tanks lined with filter paper, which were equilibrated with developing solvents for $60 \mathrm{~min}$ before insertion of the plates or papers.

Four solvent systems were utilized (Fig. 1). Solvent system I was utilized in bidirectional chromatography on Silica Gel H. Phospholipids were resolved in the first direction with chloroform: methanol: water: acetic acid $(150: 50: 4: 12 \mathrm{v} / \mathrm{v})$. The plates were then air-dried 30 min, rotated $90^{\circ}$, and the neutral lipids were resolved with light petroleum ether: ethyl ether:acetic acid (75: $25: 1 \mathrm{v} / \mathrm{v}$ ). In this system, phosphatidylserine and phosphatidylinositol were not resolved. In addition, cardiolipin, phosphatidic acid, ceramide, cerebrosides, and monoglycerides were not separated, and cholesterol and diglycerides were not resolved. Solvent system II (chloroform: methanol:7 $\mathrm{N}$ ammonia, $60: 35: 5 \mathrm{v} / \mathrm{v}$ ) applied to silicic acid-impregnated paper separated phosphatidic acid and cardiolipin from monoglycerides, ceramides, and cerebrosides that were not resolved (11). Solvent system III (chloroform: methanol: acetic acid, 95:5:5 v/v) applied to Silica Gel $\mathrm{H}$ plates resolved cerebrosides, ceramides, and monoglycerides from cholesterol and free fatty acids. Phospholipids remained at or near the origin; other neutral lipids migrated with the solvent front. Solvent system IV (ethyl ether : benzene : ethanol : acetic acid, $80: 100: 4: 0.4 \mathrm{v} / \mathrm{v}$ ) applied to Silica Gel $\mathrm{H}$ resolved cholesterol and diglycerides (12). Lipids were visible with iodine vapor or, in samples to be further analyzed by gas chromatography, by Rhodamine 6G (Allied Chemical Corp., Morristown, N. J.). In some experiments, sphingolipids were specifically made visible with the hypochlorite-benzidine reagent described by Skipski (14).

F. Preparation of methyl esters. Methyl esters of the fatty acid constituents of platelet and medium lipids were prepared by a modification of the transesterification technic of Archibald and Skipski (15). The lipid sample to be esterified was evaporated to dryness under a stream of nitrogen in a $50 \mathrm{ml}$ conical tube. The lipid was then dissolved in $0.5 \mathrm{ml}$ of benzene, after which $2 \mathrm{ml}$ of $20 \%$
$\mathrm{H}_{2} \mathrm{SO}_{4}$ in methanol was added. The flask was flushed with nitrogen and sealed. Transesterification was carried out by refluxing at $65^{\circ} \mathrm{C}$ for $1 \mathrm{hr}$. Methyl esters were recovered after the addition of $1 \mathrm{ml}$ of water by four extractions with $4 \mathrm{ml}$ of hexane. The methyl esters were purified on Silica Gel H, and were extracted from the gel with ethyl ether. Recovery of labeled lipids from the esterification reaction was complete. Recovery of radioactivity as the purified methyl esters ranged between $85-95 \%$. In some instances transesterification was carried out directly on lipids not eluted from silica gel. The gel was suspended in $0.5 \mathrm{ml}$ of benzene and the sulfuric acid-methanol added. During refluxing the gel was occasionally agitated on a Vortex mixer to assure even dispersion. Methyl esters were eluted from the gel and purified on Silica Gel $\mathrm{H}$. Recovery of radioactivity as the purified methyl esters was between $85-95 \%$.

G. Gas-liquid chromatography. Gas-liquid chromatography of the purified methyl esters was performed on an instrument ( $\mathrm{F} \& \mathrm{M}$ Scientific Corp., Avondale, $\mathrm{Pa}$. model $810)$ with dual $\frac{1}{4}$ inch $\times 6$ foot coiled columns. The stationary phase was an alkaline polar organosilicone $(1 \%$ $\mathrm{KOH}$ plus $10 \%$ EGGS-Y, on $100 / 200$-mesh gas-chrom P, Applied Science Corp.) (16). Carrier gas flow was $70 \mathrm{ml} / \mathrm{min}$. The initial column temperature was $135^{\circ} \mathrm{C}$; the temperature was progressively raised at $2^{\circ} \mathrm{C} /$ min to an upper limit of $200^{\circ} \mathrm{C}$, maintained for $40 \mathrm{~min}$. The injection port and detector temperatures were $275^{\circ} \mathrm{C}$. Retention times of individual fatty acid methyl esters were identified by comparison with National Institutes of Health reference standards $\mathrm{A}$ and $\mathrm{C}$, and by comparison with samples of highly purified individual methyl esters (Applied Science Corp.). Quantitative results agreed with the stated composition of the NIH standards with a relative error of less than $5 \%$ for both the major components ( $>10 \%$ of the total mixture) and minor components ( $<10 \%$ of the total mixture).

The effluent stream from the column was passed through a splitter that diverted $30 \%$ of the sample to the hydrogen-flame detector; the remainder was passed through a heated outlet port to a fraction collector (Packard Instruments, model 850). Individual methyl esters were trapped in glass cartridges packed with glass wool (17). Synchrony of the mass detector with the effluent port outlet was assayed before each analysis with methyl linoleate- $U-{ }^{14} \mathrm{C}$.

A carrier mixture of 15 methyl esters (C6:0-C24:0) was added to each lipid sample analyzed and individual fractions were collected. Control experiments were conducted in which trace amounts of labeled fatty acid methyl esters were added to the carrier mixture. These experiments indicated that the carrier mixture did not alter the chromatographic behavior of minute amounts of added fatty acid methyl esters. The methyl esters were quantitatively eluted from the glass wool with hexane. In other experiments the glass wool was suspended directly in counting vials containing toluene and an appropriate fluor. The radioactivity of the methyl esters could be measured directly with no loss of efficiency.

H. Fatty acid degradation studies. The radioactivity in 
the carboxyl-terminal carbon of individual fatty acids was determined by a modification of the technic described by Brady, Bradley, and Trams (18). The fatty acid methyl esters obtained by gas-liquid chromatography were hydrolyzed in methanolic $\mathrm{KOH}$ and the free fatty acids were recovered after reacidification by extraction with hexane. Each sample was placed in a $25 \mathrm{ml}$ thick-neck Erlenmeyer flask and $10 \mathrm{mg}$ of carrier palmitic acid was added. The lipid was taken to dryness under nitrogen. $50 \mathrm{mg}$ of sodium azide was added and the flask was sealed with a rubber septum that held a polyethylene cap suspended in the flask (Kontes Glass Co., Vineland, N. J., No. 88230). Degradation was initiated by the injection of $0.5 \mathrm{ml}$ of a mixture of concentrated $\mathrm{H}_{2} \mathrm{SO}_{4}$ and $30 \%$ fuming $\mathrm{H}_{2} \mathrm{SO}_{4}$, $3: 1(\mathrm{v} / \mathrm{v})$ in a hood, and care was taken not to let the acid touch the cap. The mixture was heated to $65^{\circ} \mathrm{C}$ for $60 \mathrm{~min}$, after which the samples were transferred to an ice bath, and $0.2 \mathrm{ml}$ of the quarternary base NCS reagent (Nuclear Chicago Co.) was injected into the cup. Evolved $\mathrm{CO}_{2}$ was absorbed by the NCS reagent during a further incubation of the flask at $37^{\circ} \mathrm{C}$ for $35 \mathrm{~min}$. The septum and cup were then removed and the cup was placed directly into a counting vial that contained toluene and fluor. There was no significant quenching of radioactivity. In control experiments $89 \%$ of the radioactivity in acetic acid- $1-{ }^{14} \mathrm{C}$ and $86 \%$ of the radioactivity of palmitic acid- $1{ }^{14} \mathrm{C}$ were recovered as $\mathrm{CO}_{2}$; less than $0.5 \%$ of the radioactivity in acetic acid- $2-{ }^{14} \mathrm{C}$ or palmitic acid$16-{ }^{14} \mathrm{C}$ was recovered as $\mathrm{CO}_{2}$, which indicated a high degree of specificity and acceptable recovery of radioactivity with this technic.

I. Assay of radioactivity. The radioactivity of lipid extracts was measured by liquid scintillation counting with a fluor, prepared by adding $42 \mathrm{ml}$ of Liquifluor (New England Nuclear Corp.) to 1 liter of toluene. The radioactivity of lipids separated on Silica $\mathrm{Gel} \mathrm{H}$ was determined either by elution of lipid from the gel or by direct suspension of the gel in $15 \mathrm{ml}$ of a thixatropic solution (Cab-O-Sil, Packard Instrument Co.), prepared by adding $3.9 \mathrm{~g}$ of Cab-O-Sil to $100 \mathrm{ml}$ of Liquifluor-toluene. The radioactivity of samples isolated by paper chromatography was assayed by cutting the appropriate spots from the paper and then placing the paper in vials containing $15 \mathrm{ml}$ of Liquifluor-toluene. Counting efficiency for ${ }^{14} \mathrm{C}$ was approximately $84 \%$ with a three-channel spectrometer (Nuclear-Chicago Corp.). Corrections for quenching were performed, where appropriate, with an external standard.

\section{RESULTS}

\section{A. Incubations with acetate-1-14 $\mathrm{C}$}

Optimal incubation conditions were established in a series of initial experiments. The incorporation of acetate into platelet lipids was found to be a linear function of the platelet concentration over a wide range $\left(0.5-7.0 \times 10^{9}\right.$ platelets $\left./ \mathrm{ml}\right)$ in both buffer and plasma incubation media. There was a sharp optimum for the rate of acetate incorporation by platelets incubated in buffer at $\mathrm{pH} 6.8$, with an abrupt decline to less than $55 \%$ of peak incorporation at $\mathrm{pH}$ 7.2. With platelets suspended in plasma there was a broad optimal $\mathrm{pH}$ range between 6.8-7.4. At $\mathrm{pH}$ 6.8, incorporation in buffer slightly exceeded that in plasma, whereas at higher $\mathrm{pH}$ values the reverse was true. The maximal total incorporation occurred at $\mathrm{pH} 6.8$, and this value was used in all subsequent studies. The effect of substrate concentration was studied in both buffer and plasma media. In both media, increasing acetate concentrations to 1.5 mmoles/ liter stimulated incorporation, with little additional stimulation at higher acetate concentrations. In subsequent incubations the acetate concentration was fixed at $2.5 \mathrm{mmoles} /$ liter. The maximal rate of acetate incorporation was $0.8 \mathrm{~m} \mu$ moles $/ 10^{\circ}$ platelets per hr in both plasma and buffer media. (At a substrate SA of $2.0 \mu \mathrm{c} / \mu$ moles, the typical count incorporation was approximately $2000 \mathrm{cpm} /$ $10^{9}$ platelets per $\mathrm{hr}$.)

The partition of newly synthesized lipids between intra- and extracellular phases was markedly influenced by the composition of the incubation medium. When platelets were incubated with acetate- $1{ }^{14} \mathrm{C}$ in buffer, Iess than $5 \%$ of the total radioactivity appeared in the medium. Replacement of only $0.1 \mathrm{ml}$ of buffer by an equivalent amount of dialyzed plasma stimulated nearly maximal release of radioactivity, which reached $40 \%$ of the total when the incubation medium contained $1.0 \mathrm{ml}$ of dialyzed plasma.

The distribution of radioactivity among individual lipid classes was determined by thin-layet and paper chromatography. In initial studies platelets were incubated with acetate $-1{ }^{14} \mathrm{C}$ in triplicate in both buffer and plasma and the entire contents of the incubation flasks were extracted. After portions of the washed chloroform phases were withdrawn to determine total count incorporation, the chloroform phases were dried, and fatty acid methyl esters of the lipid residue were prepared and purified. Of the total radioactivity in both buffer and plasma incubations, $83-96 \%$ was recovered as purified methyl esters. Since the recovery of control samples of tripalmitin and palmitic acid carried throughout the same procedures was also between $85-95 \%$, the data indicated that the ace- 


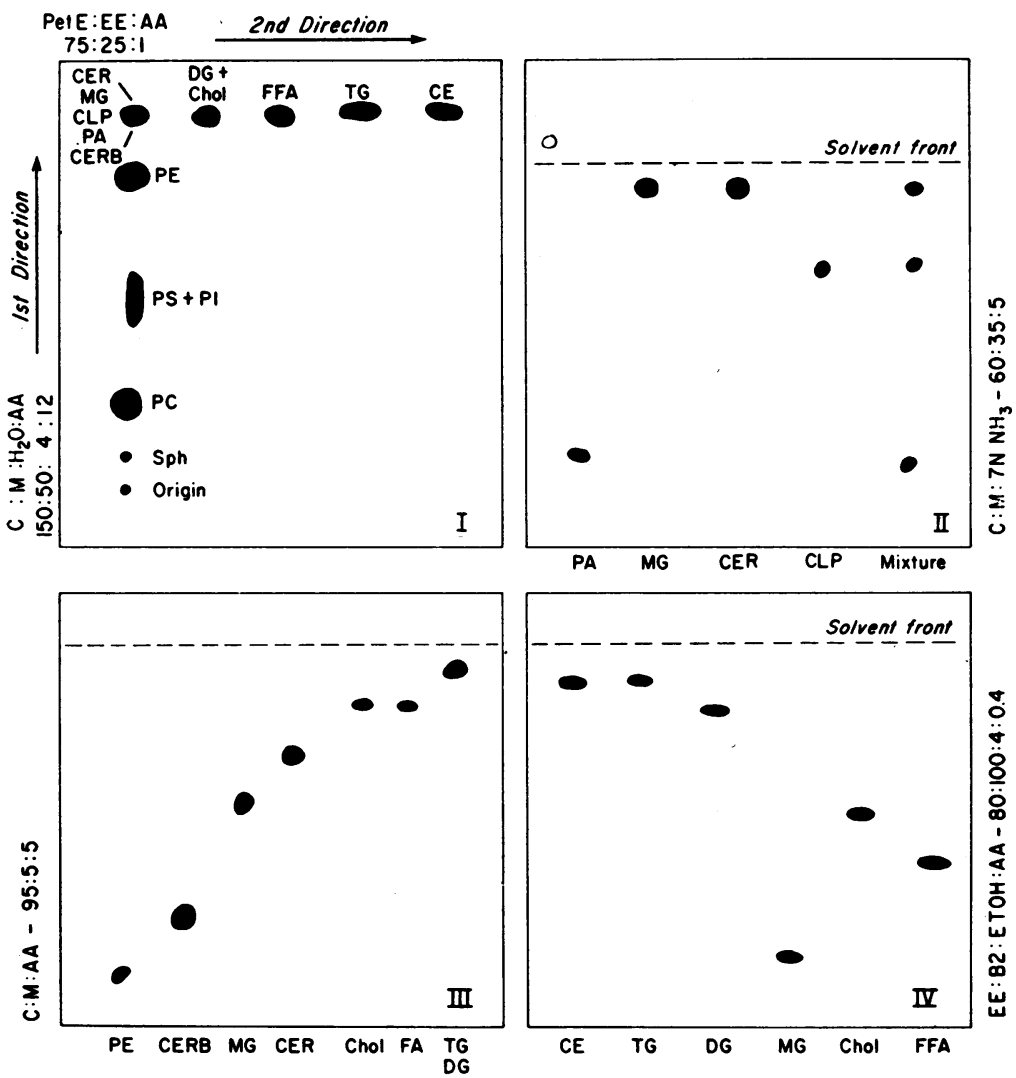

FIGURE 1 Chromatographic systems for resolving platelet lipids. Sph, sphingomyelin; PC, phosphatidylcholine (lecithin) ; PS, phosphatidylserine; PI, phosphatidylinositol; PE, phosphatidylethanolamine; PA, phosphatidic acid; CLP, cardiolipin; CER, ceramide; CERB, cerebroside; $M G$, monoglyceride; DG, diglyceride; TG, triglyceride; FFA, free (unesterified) fatty acids; Chol, cholesterol ; $\mathrm{CE}$, cholesteryl esters; PetE, petroleum ether; EE, ethyl ether; C, chloroform; M, methanol; AA, acetic acid (glacial); ETOH, ethanol; BZ, benzene.

tate was incorporated primarily into the fatty acid moiety of platelet lipids.

In further exploratory studies with solvent system I (Fig. 1) to separate lipid classes, $30-45 \%$ of the total radioactivity in both plasma or buffer incubations was found in the "corner" in which phosphatidic acid, cardiolipin, cerebrosides, ceramides, and monoglycerides were unresolved. In solvent system II (Fig. 1), however, no radioactivity was found in either phosphatidic acid or cardiolipin. In solvent system III (Fig. 1), less than $1 \%$ of the total radioactivity was present in the monoglyceride fraction, and the cerebroside area also contained no radioactivity. However, all of the radioactivity initially isolated from the corner area in solvent system I migrated as ceramide in system III. In additional studies platelets were incubated in either plasma or buffer with acetate $-1{ }^{14} \mathrm{C}$, and the total lipid extracts were applied to $5 \mathrm{~g}$ silicic acid columns. The lipids were eluted from the columns serially with chloroform $(400 \mathrm{ml})$, chloroform: methanol $(1: 1 \mathrm{v} / \mathrm{v}) \quad(100$ $\mathrm{ml})$, and finally methanol $(100 \mathrm{ml})$. The lipids eluted with each solvent were applied to thin-layer plates and were developed in solvent system I. The radioactivity present in the corner area was eluted from the silicic acid columns with chloroform alone.

The identity of the radioactive compound in the corner was further characterized by examining the alkali-lability of the fatty acid linkage to the 
parent compound (Table I). After $16 \mathrm{hr}$ of hydrolysis under vigorous conditions, only $67 \%$ of the fatty acids was released from the compound. Under similar conditions, hydrolysis of platelet lecithin, phosphatidylethanolamine, and triglycerides was $95 \%$ complete. In a separate experiment, hydrolysis of purified mono-olein-1-14C under these conditions was essentially complete in $5 \mathrm{~min}$.

The presence of platelet sphingolipid in the appropriate ceramide areas was established by developing one portion of a total platelet lipid extract in solvent system I and another portion in solvent system III. The plates were sprayed with the hypochlorite-benzidine sphingolipid reagent. An intense blue color in the sphingomyelin area and a distinct blue color in the corner developed in solvent system I, and a blue color at the origin and at the ceramide area developed in solvent system III.

In other experiments platelets were incubated in buffer with acetate- $1{ }^{14} \mathrm{C}$ and the resulting labeled lipid extract was initially chromatographed in solvent system I. The corner area was eluted from the plate, and carrier ceramide $(100 \mu \mathrm{g})$ was added to the extract. The mixture was then chromatographed on a second thin-layer plate in solvent system III. A photographic film was applied to the plate and was exposed for 5 days. The lipids were identified on the thin-layer plate by exposure to iodine vapor. Three spots were identified, one of which corresponded to ceramide.

TABLE I

Alkaline Hydrolysis of Platelet Ceramide*

\begin{tabular}{cc}
\hline Time of incubation & Hydrolysis \\
\hline $\min$ & $\%$ \\
$0 \ddagger$ & 2.3 \\
30 & 9.6 \\
60 & 18.1 \\
120 & 29.8 \\
240 & 52.1 \\
360 & 52.2 \\
960 & 67.6
\end{tabular}

* Mean of duplicate experiments. Ceramide was isolated from platelet extracts (solvent system III) after incubation in buffer with $\mathrm{Na}$ acetate-1-14 $\mathrm{C}$. Hydrolysis was conducted at $65^{\circ} \mathrm{C}$ in $5 \mathrm{C}_{\mathrm{C}}$ methanolic $\mathrm{KOH}$, and the products, recovered after reacidification, were identified by thin-layer chromatography on Silica Gel H.

$\ddagger$ Lipid added to hydrolysis mixture and immediately extracted.
The photographic film revealed only one area of radioactivity that corresponded precisely with the contour of the ceramide. The radioactivity was distributed uniformly throughout the spot, indicating uniform dilution of the endogenous platelet radioactive compound by the added carrier ceramide.

On the basis of the migration in solvent systems I and III, the relative resistance of the fatty acid bond to alkaline hydrolysis, the demonstration that ceramide could be identified in platelet lipid extracts, and the isotope "dilution" by carrier ceramide by radioautography, the radioactivity that accumulated in the corner in solvent system I was identified as ceramide.

The distribution of radioactivity incorporated from acetate-1-14 $\mathrm{C}$ among the platelet lipid classes showed striking differences between buffer or plasma incubations. In buffer (Fig. $2 A$ ), of the total radioactivity $22 \%$ was found in lecithin, $46 \%$

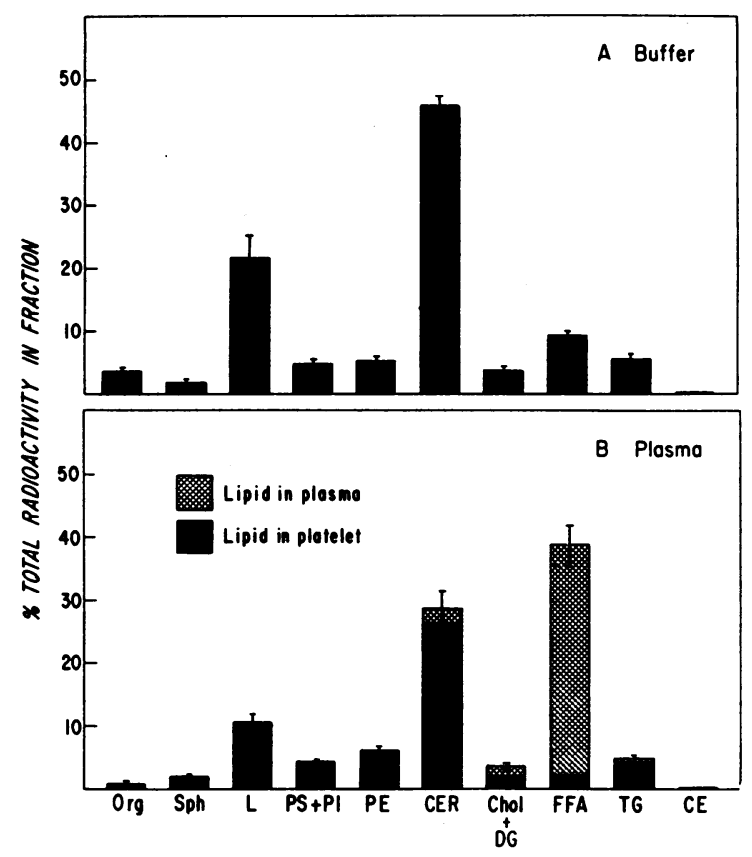

FIgURE 2 Distribution of radioactivity among platelet lipid classes after incubation with acetate $-1-{ }^{14} \mathrm{C}$. Each flask contained, in a final volume of $2.2 \mathrm{ml}, 1.0 \mathrm{ml}$ of washed human platelet suspension, $1.0 \mathrm{ml}$ of either buffer or dialyzed plasma, and $5.5 \mu$ moles of $\mathrm{Na}$ acetate $-1-{ }^{14} \mathrm{C}$ (SA $2 \mu \mathrm{c} / \mu \mathrm{mole}$ ). Incubations were conducted under $95 \%$ $\mathrm{O}_{2}$ and $5 \% \mathrm{CO}_{2}$ for $60 \mathrm{~min}$. $A$, incubation in buffer. Mean $\pm \mathrm{SE}, 10$ experiments. $B$, incubations in plasma. Mean \pm sE, five experiments. 
in ceramide, and $9 \%$ in unesterified fatty acids, with lesser amounts in the other lipid classes. The radioactivity in the buffer medium (less than $5 \%$ of the total) was not analyzed. In plasma incubations (Fig. $2 \mathrm{~B}$ ), of the total radioactivity $11 \%$ was present in lecithin, $29 \%$ in ceramide, and $39 \%$ in free fatty acids. The bulk of the free fatty acid radioactivity was recovered in the plasma, and represented $85 \%$ of the total radioactivity in the plasma medium.

In separate experiments with solvent systems I and IV, we determined that in buffer incubations, of the radioactivity present in the combined cholesterol-diglyceride fraction in solvent system I, 38\% was cholesterol and $62 \%$ diglyceride, whereas in plasma incubations $74 \%$ was cholesterol and $26 \%$ diglyceride.

The time-course of acetate incorporation into platelet lipids was examined in both buffer and plasma incubations. The rate of acetate incorporation into total lipids was linear in both incubation media for 60 min (Figs. $3 A$ and $B$ inserts). In buffer, however, there were striking deviations from linearity in the rate of acetate incorporation into individual lipid classes (Fig. $3 A$ ). After an initial lag, the rate of acetate incorporation into lecithin accelerated markedly. Conversely, the rate of acetate incorporation into free fatty acids, initially exceeding that into lecithin, fell off sharply with little further net incorporation that occurred after $15 \mathrm{~min}$. The rate of incorporation into ceramide was linear for the initial $30 \mathrm{~min}$, but declined slightly thereafter. In plasma incubations the rate of incorporation of acetate into lecithin, free fatty acids, and ceramide was linear for 60 min (Fig. $3 B$ ). The distribution of radioactivity between platelets and plasma (40\% of the total present in plasma) was constant throughout the incubation.

The composition of fatty acids formed from acetate was determined in both buffer and plasma incubations. The distribution of radioactivity among the fatty acids of the total lipids of platelets incubated in buffer was determined by preparing the methyl esters of a total lipid extract of the platelets after incubation. (The buffer medium was not analyzed.) The distribution of radioactivity among the fatty acids of the total lipids of platelets incubated in plasma was determined by preparing methyl esters of the combined platelet and plasma medium extracts (Table II, A). Under these conditions the distribution of radioactivity among the fatty acid classes was similar in both types of incubations. Less than $30 \%$ of the total fatty acid radioactivity was present in myristic and palmitic acids.

The distribution of radioactivity in the fatty acids of individual lipid classes was determined
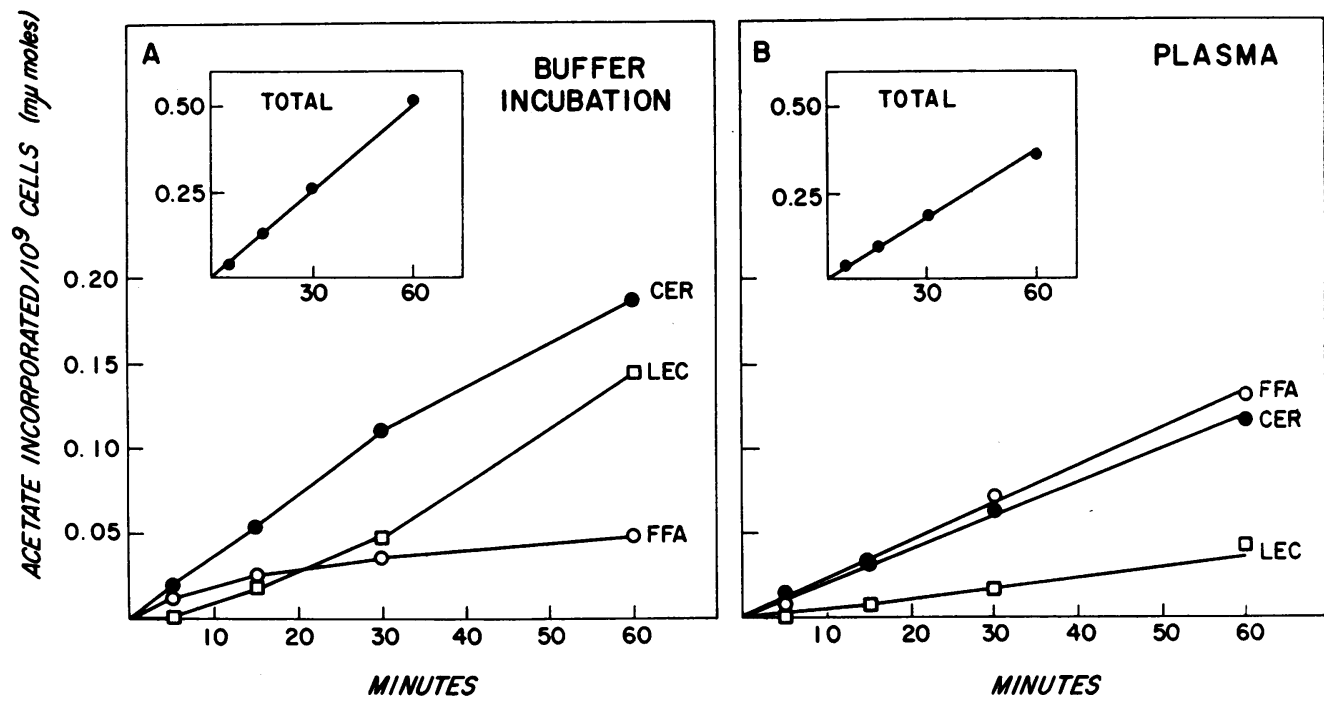

FIGURE 3 Time-course of incorporation of acetate into platelet lipids. Mean of triplicate experiments. $A$, incubation in buffer. Insert: acetate incorporation into platelet total lipids. $B$, incubation in plasma. Insert: acetate incorporation into lipids of platelets plus plasma. 
TABLE II

Fatty Acid Distribution of Radioactivity-Na Acetate-1-14C Incubations

\begin{tabular}{|c|c|c|c|c|c|c|c|c|c|c|c|c|}
\hline & \multicolumn{6}{|c|}{ Buffer incubations* } & \multicolumn{6}{|c|}{ Plasma incubations $\ddagger$} \\
\hline & C14:0 & $\mathrm{C} 16: 0$ & $\begin{array}{c}\text { C18:0 } \\
\text { plus } \\
\text { C18:1 } \\
\text { plus } \\
\text { C18:2 }\end{array}$ & C20:0 & $\begin{array}{c}\text { C22:0 } \\
\text { plus } \\
\text { C20:4 }\end{array}$ & $\begin{array}{c}\text { C24:0 } \\
\text { plus } \\
>\text { C24:0 }\end{array}$ & C14:0 & C16:0 & $\begin{array}{c}\text { C18:0 } \\
\text { plus } \\
\text { C18:1 } \\
\text { plus } \\
\text { C18:2 }\end{array}$ & C20:0 & $\begin{array}{c}\text { C22:0 } \\
\text { plus } \\
\text { C20:4 }\end{array}$ & $\begin{array}{r}\text { C24:0 } \\
\text { plus } \\
>\text { C24:0 }\end{array}$ \\
\hline A Whole platelets§ & 6.5 & 15.2 & 10.3 & 24.1 & 22.5 & 21.4 & 12.1 & 17.3 & 8.2 & 18.4 & 15.6 & 28.5 \\
\hline \multicolumn{13}{|l|}{$\begin{array}{l}\text { B Individual lipid } \| \\
\text { classes }\end{array}$} \\
\hline Lecithin & 14.5 & 35.5 & 16.3 & 20.7 & 7.9 & 5.2 & 0.7 & 6.8 & 18.5 & 38.7 & 13.4 & 21.1 \\
\hline PS plus PI & 2.5 & 24.6 & 34.8 & 24.2 & 8.3 & 5.6 & 0.9 & 5.4 & 25.2 & 43.0 & 14.4 & 11.4 \\
\hline $\mathrm{PE}$ & 3.4 & 36.0 & 25.3 & 18.9 & 8.2 & 8.3 & 0.3 & 5.8 & 17.1 & 39.2 & 14.8 & 17.9 \\
\hline Diglyceride & 7.3 & 9.7 & 5.8 & 47.8 & 12.5 & 16.5 & 1.1 & 3.9 & 4.6 & 49.6 & 19.9 & 20.9 \\
\hline Triglyceride & 7.6 & 19.4 & 8.6 & 32.4 & 19.4 & 13.9 & 1.3 & 2.1 & 5.7 & 52.1 & 20.6 & 18.3 \\
\hline Ceramide & 0.6 & 4.2 & 1.6 & 21.8 & 48.7 & 22.7 & 0.1 & 0.7 & 1.0 & 15.1 & 55.1 & 28.0 \\
\hline $\begin{array}{l}\text { Free fatty acid } \\
\quad \text { (intracellular) }\end{array}$ & 21.6 & 24.5 & 7.5 & 22.9 & 12.1 & 11.4 & 6.1 & 6.6 & 5.0 & 37.7 & 25.1 & 22.6 \\
\hline $\begin{array}{l}\text { Free fatty acid } \\
\quad \text { (extracellular) }\end{array}$ & - & - & - & - & - & - & 24.8 & 51.2 & 5.1 & 8.5 & 6.1 & 4.1 \\
\hline
\end{tabular}

* Mean of triplicate experiments. Per cent of radioactivity in platelets only.

$\ddagger$ Mean of triplicate experiments. Per cent of radioactivity in platelets plus medium.

$\S$ Per cent of radioactivity in total platelets or total platelets + medium.

$\|$ Per cent of radioactivity in each lipid class. Intra- and extracellular free fatty acids analyzed separately.

by separating the lipid classes by thin-layer chromatography (solvent system I) before preparing the methyl esters. In these studies, plasma-containing media were analyzed separately; buffer media were not examined (Table II, B). In buffer incubations, in the lecithin and free fatty acid fractions approximately half of the radioactivity was present in myristic and palmitic acids. In ceramide, however, less than $5 \%$ of the radioactivity was present in myristic or palmitic acids, and over $70 \%$ of the radioactivity was present in fatty acids containing 22 or more carbon units. The distribution in the other lipid classes was intermediate between the lecithin and ceramide patterns.

In plasma incubations, there was less radioactivity in myristic and palmitic acids, throughout all the intracellular lipid classes. In the extracellular plasma medium, however, over $75 \%$ of the radioactivity in the free fatty acids (which constituted the bulk of the radioactivity) was present in myristic and palmitic acids.

Fatty acid degradation studies were performed after incubation with acetate- $1-{ }^{14} \mathrm{C}$ on fatty acids isolated from each lipid class in both buffer and plasma media, and the percentage of the radio- activity in each fatty acid class present in the carboxyl carbon was determined. Analysis of the data revealed no significant variation of the percentage of the carboxyl carbon radioactivity in individual fatty acids among the lipid classes nor between buffer and plasma incubations. Therefore, the data from each fatty acid class were pooled for final presentation (Table III). There were marked fluctuations in samples containing less than $100 \mathrm{cpm}$ and these were excluded. It was apparent that of the newly synthesized myristic and palmitic acids, both were formed exclusively by de novo synthesis from acetate, whereas the remaining free fatty acids were formed by both de novo and chain elongation processes.

The turnover of platelet lipids was examined with acetate-1-14 $\mathrm{C}$ incubations. Five identical flasks containing platelets in a buffer medium were incubated with $5.5 \mu$ moles of acetate- $1{ }^{14} \mathrm{C}$ (SA $26.4 \mathrm{mc} / \mathrm{mmole}$ ) for $60 \mathrm{~min}$. The contents of the flasks were pooled and an excess of unlabeled acetate was added to stop further uptake of radioactivity. The pooled platelet suspension was redivided into three groups. To the first group (A) buffer was added and the lipids were extracted 
TABLE III

Carboxyl Carbon Radioactivity*-Acetate-1-14 C Incubations

\begin{tabular}{cccccc}
\hline C14:0 & C16 & $\begin{array}{c}\text { C18:0 } \\
\text { plus } \\
\text { C18:1 } \\
\text { plus } \\
\text { C18:2 }\end{array}$ & C20:0 & $\begin{array}{c}\text { C22:0 } \\
\text { plus } \\
\text { C20:4 }\end{array}$ & $\begin{array}{c}\text { C24:0 } \\
\text { plus } \\
\text { C24:0 }\end{array}$ \\
\hline $12.0 \ddagger$ & $13.8 \pm 1.54$ & $71.8 \pm 8.45$ & $61.9 \pm 5.72$ & $54.4 \pm 3.98$ & $56.9 \pm 4.79$ \\
\hline
\end{tabular}

* Per cent of total radioactivity in each fraction present in carboxyl carbon. Mean \pm SEM, 6-12 determinations of each chain length group.

$\ddagger$ Single determination.

immediately. To the second group (B) buffer was added and the platelets were incubated for an additional $60 \mathrm{~min}$, after which the lipids were extracted. To the final group $(\mathrm{C})$ dialyzed plasma was added and the platelets were incubated for $60 \mathrm{~min}$, whereupon the platelets were then separated from the plasma medium. The lipids of the platelets and plasma were extracted separately (C-platelets, C-plasma). A portion (10\%) of each lipid extract was chromatographed on thin-layer plates using solvent system I (Table IV). There were no significant differences between groups $A$ and $B$, and the pattern of radioactivity was similar to that shown in Fig. $2 \mathrm{~A}$. In group $\mathrm{C}$, however, there was a marked decrement in intracellular lecithin and free fatty acid radioactivity. Conversely, there was a pronounced rise in extracellular free fatty acid radioactivity. There were no alterations in the distribution of radioactivity in other lipid classes. No radioactivity appeared in the area corresponding to lysolecithin.
The remainder of the total lipid extracts was also separated into lipid classes (solvent system I) and the methyl esters of the fatty acids were prepared by direct transesterification of the lipids on the silica gel. The fatty acid radioactivity distribution of the lecithin, ceramide, and free fatty acid fractions of each group are summarized in Table V. There was no difference between fatty acid distribution in groups A and B. However, in group $\mathrm{C}$, a decrement in lecithin palmitic and myristic acid labeling was evident, as was a more striking decrease in intracellular free fatty acid palmitic and myristic radioactivity. There was no significant change in the ceramide fraction. In the plasma medium, the label in free fatty acids was predominantly, although not exclusively, found in myristic and palmitic acids.

The data presented in Tables IV and V indicate that in buffer incubations, when further accumulation of radioactivity from acetate was blocked by excess unlabeled acetate, no turnover of intra-

TABLE IV

Distribution of Radioactivity among Individual Lipid Classes-Turnover Study*

\begin{tabular}{lrrrrr}
\hline \multicolumn{1}{c}{ Lipid class } & $\mathrm{A}$ & $\mathrm{B}$ & $\mathrm{C}_{\text {platelet }}$ & $\mathrm{C}_{\text {plasma }}$ & $\mathrm{C}_{\text {total }}$ \\
\hline & & \multicolumn{2}{c}{ \% total radioactivity in each class } \\
Lecithin & 17.4 & 15.9 & 7.6 & 0.8 & 8.4 \\
PS plus PI & 4.6 & 4.8 & 3.9 & 0.2 & 4.1 \\
PE & 4.9 & 4.7 & 3.4 & 0.2 & 3.6 \\
Ceramide & 46.6 & 49.1 & 39.1 & 3.2 & 41.3 \\
Diglyceride plus cholesterol & 4.9 & 3.8 & 2.1 & 2.7 & 4.8 \\
Triglyceride & 6.2 & 5.8 & 4.6 & 1.7 & 6.3 \\
Free fatty acids & 11.5 & 12.4 & 3.0 & 25.1 & 28.1 \\
Total cpm $/ 10^{9}$ platelets & 18,380 & 21,850 & 16,180 & 7,700 & 23,800 \\
\hline
\end{tabular}

* Platelets incubated in buffer for $60 \mathrm{~min}$ with $\mathrm{Na}$ acetate- $1{ }^{14} \mathrm{C}(5.5 \mu \mathrm{moles}, \mathrm{SA} 7 \mu \mathrm{c} / \mathrm{mole})$. at $60 \mathrm{~min}, 800 \mu \mathrm{moles}$ of unlabeled acetate was added and the platelets were divided into three groups: A, platelets extracted at 60 min; B, platelets incubated for an additional $60 \mathrm{~min}$ in buffer; $\mathrm{C}$, platelets incubated for an additional $60 \mathrm{~min}$ in plasma. 
TABLE V

Fatty Acid Distribution of Radioactivity-Turnover Study

\begin{tabular}{lrrrc}
\hline & $\mathrm{A}$ & $\mathrm{B}$ & $\mathrm{C}_{\text {platelets }}$ & $\mathrm{C}_{\text {plasms }}$ \\
\hline & \multicolumn{4}{c}{ \% total radioactivity in each class } \\
Lecithin & & & & \\
$\quad$ C14:0 plus C16:0 & 55.2 & 52.4 & 41.2 & - \\
$\quad>$ C16:0 & 44.8 & 47.6 & 58.8 & - \\
Ceramide & & & & \\
$\quad$ C14:0 plus C16.0 & 3.1 & 3.2 & 1.7 & - \\
$>$ C16:0 & 96.4 & 96.8 & 98.3 & - \\
Free fatty acid & & & & \\
C14:0 plus C16:0 & 47.2 & 50.0 & 15.6 & 61.4 \\
$>$ C16:0 & 52.8 & 50.0 & 84.4 & 38.6 \\
\hline
\end{tabular}

* Conditions as in Table IV.

cellular lipids could be demonstrated, but that in the presence of plasma, turnover of lecithin was evident.

\section{B. Incubations with palmitic acid-1-14C}

The pattern of incorporation of palmitic acid$1-{ }^{14} \mathrm{C}$ into platelet lipids is presented in Table VI, column 1 . Over $50 \%$ of the palmitic acid taken up was recovered in lecithin, with a rather uniform distribution into the other lipid classes. From the distribution of total radioactivity in each lipid class (Fig. 2) and from the distribution of radioactivity among the individual fatty acids in each lipid class (Table II, B), it was possible to determine the percentage of total radioactivity incorporated from acetate present as palmitic acid in each lipid class (Table VI, columns 2 and 3 ). The distribution of

TABLE VI

Distribution of Palmitic Acid Radioactivity among Intracellular Platelet Lipid Classes

\begin{tabular}{|c|c|c|c|}
\hline Lipid class & $\mathrm{I}^{*}$ & II & III \\
\hline & \multicolumn{3}{|c|}{$\%$ total palmitic acid radioactivit } \\
\hline Lecithin & 53.9 & 46.5 & 38.6 \\
\hline PS plus PI & 7.0 & 10.0 & 13.5 \\
\hline $\mathrm{PE}$ & 6.0 & 14.6 & 17.7 \\
\hline Ceramide & 7.7 & 9.8 & 10.9 \\
\hline Diglyceride & 4.1 & 2.6 & 6.8 \\
\hline Triglyceride & 10.2 & 5.7 & 4.7 \\
\hline Free fatty acids & 5.7 & 10.8 & 7.8 \\
\hline
\end{tabular}

* I, incubation in plasma containing $5 \mu \mathrm{c}$ palmitic acid$1-{ }^{14} \mathrm{C}$. Mean of duplicate experiments. II, Incubation in buffer, with $\mathrm{Na}$ acetate-1-14 $\mathrm{C}$. III, Incubation in plasma with $\mathrm{Na}$ acetate-1-14 C. Intracellular lipids only. Groups II and III calculated from Fig. 2 and Table II. palmitic acid formed from acetate- $1-{ }^{14} \mathrm{C}$ among the intracellular lipid classes in buffer incubations closely resembled that found when palmitic acid${ }^{1-14} \mathrm{C}$ was incorporated from a plasma medium. Similarly, although the total intracellular radioactivity present as palmitic acid was sharply reduced in plasma incubations with acetate- $1-{ }^{14} \mathrm{C}$, the distribution of intracellular palmitic acid was again similar to that of the palmitic acid $-1-{ }^{14} \mathrm{C}$ experiments. In other experiments, after incubation of platelets with palmitic acid- $1-{ }^{14} \mathrm{C}$, total platelet extracts were prepared and the distribution of radioactivity among the fatty acids was determined by gas-liquid chromatography. Of the total radioactivity, $96 \%$ was recovered as palmitic acid, consistent with the original radiopurity of the preparation.

\section{DISCUSSION}

In their study of the incorporation of acetate into leukocytes and platelets, Marks, Gellhorn, and Kidson (1) indicated that on a per cell basis the rate of incorporation of acetate into leukocytes was 70-fold that of platelets. Their data indicate a maximal leukocyte uptake of acetate equivalent to approximately $110 \mathrm{~m} \mu$ moles of acetate per $10^{\circ}$ leukocytes $/ 2 \frac{1}{2} \mathrm{hr}$ (expressed as $90 \mathrm{mg} \times 10^{-7}$ acetate $/ 10^{6} \mathrm{WBC}$ leukocytes per $2 \frac{1}{2} \mathrm{hr}$ ). Assuming a linear rate of incorporation during the incubation, their data could be expressed as $44 \mathrm{~m} \mu$ moles of acetate incorporated per $10^{9}$ leukocytes/ $2 \frac{1}{2} \mathrm{hr}$. Therefore, the maximal rate of uptake of acetate into platelets calculated from their data is approximately $0.6 \mathrm{~m} \mu$ mole $/ 10^{9}$ platelets per $\mathrm{hr}$. In the present study, the maximal rate of acetate incorporation into platelets was $0.8 \mathrm{~m} \mu \mathrm{mole} /$ $10^{9}$ platelets per hr, confirming the earlier findings of Marks et al. (1). Our data indicate that the peak acetate incorporation occurred at a substrate concentration 10-fold less than that required for optimum leukocyte incorporation of acetate.

The distribution of newly synthesized lipids among individual lipid classes (Fig. 2) differs from that of previous studies. Marks et al. (1) reported that the bulk of intracellular platelet radioactivity was present in the neutral lipid fraction (presumed to be primarily glycerides and free fatty acids) and that extracellular radioactivity also consisted primarily of neutral lipids. Hennes, Awai, and Hammarstrand (6), who ex- 
amined the combined total lipids in platelets and plasma after incubation of platelet-rich plasma with acetate $-1-{ }^{14} \mathrm{C}$, found $47 \%$ of the total radioactivity present in free fatty acids, $29 \%$ in phospholipids, and $21 \%$ in glycerides. Our findings, however, indicate that there was a striking accumulation of radioactivity in the neutral sphingolipid, ceramide, and that there was relatively scanty accumulation of radioactivity in the glycerides. Under the conditions of separation of lipid classes utilized in the prior investigations, ceramide may well have been included in the fractions containing glycerides.

Miras. Mantzos, and Levis (19) have reported that in incubation of rabbit thymus homogenates with acetate $-1-{ }^{14} \mathrm{C}$, the labeled fatty acids formed were present primarily in a compound whose migration on thin-layer chromatography was more rapid than cerebrosides but less than that of neutral lipids. Furthermore, only $10-30 \%$ of the fatty acids were present in a bond that could be cleaved by alkaline hydrolysis. These findings are similar to ours. Since there have been few studies in which the presence of radioactivity in ceramide was specifically examined, it is not clear whether the preferential synthesis of ceramide from acetate is a highly specific reaction confined to platelets and thymus or a reaction of more widespread distribution.

The distribution of newly synthesized lipids between platelets and extracellular medium was markedly affected by the composition of the medium. In the absence of an acceptor protein, less than $5 \%$ of labeled lipid was released into buffer. Small amounts of plasma maximally stimulated the release of radioactivity, present primarily in free fatty acids (Fig. 2). Spector and Steinberg (20) have recently summarized the other tissues known to release fatty acids into an albumin-containing medium. They include: adipose tissue, lung, heart, and ascites tumor cells. The data of Marks et al. (1) and Malamos, Miras, Levis, and Mantzos (2) suggest that leukocytes release free fatty acids as well. It is clear that in the case of adipose tissue, net release of free fatty acids can be readily demonstrated. However, whether or not net release (in contrast to isotopic exchange) occurs in other tissues depends on a complex relationship between cellular fatty acid concentration and the molar ratio of free fatty acid to albumin in the extra- cellular medium (20). In the platelet, the concentration of free fatty acids is so low as to be undetectable by conventional technics $(21,22)$. Under these circumstances the appearance of radioactivity in extracellular free fatty acids clearly represents exchange of labeled free fatty acid between intracellular sites and a large unlabeled pool of albumin-bound plasma free fatty acids, which acts as a trapping mechanism for labeled free fatty acids formed within the platelet.

The time-course of incorporation of acetate into platelet lipids (Fig. 3) is also consistent with the trapping of fatty acid radioactivity in a large extracellular pool. In both buffer and plasma incubations, the rate of ceramide synthesis was linear, but there were marked differences in the rates of labeling of fatty acid and lecithin that varied inversely. Because it was not possible to determine the specific activity of the intracellular free fatty acid pool, it is not possible to state with certainty that the free fatty acid pool was the direct precursor of at least a portion of the acyl moieties in lecithin, although the data are consistent with such an interpretation.

In plasma, the rates of acetate incorporation into free fatty acids and lecithin fatty acids were linear. The data are consistent with the suggestion that a portion of the newly formed fatty acids rapidly exchanged with the extracellular free fatty acid pool, thereby diverting the incorporation of the radioactivity in those fatty acids from lecithin. The accumulation of radioactivity in lecithin during plasma incubations presumably reflects incorporation from a less readily exchangeable intracellular fatty acid pool.

The shift between intra- to extracellular distribution of specific fatty acids is consistent with nonhomogeneous intracellular free fatty acid pools. Although myristic and palmitic acids contained less than $30 \%$ of the total radioactivity in both buffer and plasma incubations (Table II, A) over $75 \%$ of the extracellular free fatty acid label, in plasma incubations, was present in those acids (Table II, B). Concomitantly, there was a marked decrease in palmitic and myristic acid labeling among intracellular complex lipids when platelets were incubated in plasma rather than buffer. The radioactivity in ceramide was confined almost entirely to fatty acids longer than palmitic acid, and no alteration in the distribution of radioactivity in 
ceramide fatty acids was noted in buffer or plasma incubations.

Further evidence for free exchange of palmitic acid between platelets and plasma is provided by the incorporation of palmitic acid- $1-{ }^{14} \mathrm{C}$. The intracellular distribution of palmitic acid- $1-{ }^{14} \mathrm{C}$ was essentially similar to that of palmitic acid formed de novo within the cell (Table VI). The failure to detect incorporation of palmitic acid- $1-{ }^{14} \mathrm{C}$ into longer chain fatty acids indicates that there was little equilibration between the sites of de novo synthesis and those of chain elongation. Therefore, our data indicate that palmitic and myristic acids, formed intracellularly by de novo synthesis (Table III), exchange freely with plasma free fatty acids, and that there is limited intracellular equilibration between the sites of production of exchangeable fatty acids with those sites at which preformed fatty acids are chain-elongated.

The data presented in Tables IV and V indicate significant turnover of platelet lecithin during incubations in plasma. Lecithin turnover has been studied extensively in homogenates of polymorphonuclear leukocytes (23). It has been shown that such homogenates can degrade lecithin to lysolecithin and resynthesize lecithin from the monoacyl derivative through two well-established pathways $(24,25)$. In one, lysolecithin is directly acylated to form lecithin; in the other a transfer of an acyl group from one lysolecithin to a second produces lecithin and the water soluble derivative, gylceryl phosphoryl choline. In the present study, there was no accumulation of radioactivity in lysolecithin. However, in the presence of an effective trapping mechanism in the extracellular medium, no radioactivity in any intracellular lipid would be demonstrable if the mechanism of turnover proceeded through an exchangeable free fatty acid intermediate. Since the radioactivity in our study was confined almost entirely to acyl residues, our data do not distinguish between the two major pathways of lecithin turnover. It is apparent, however (Table IV, column B and Table V, column $B)$, that in buffer no turnover of lecithin was demonstrable. Thus, an acyl group could not be cleaved from platelet lecithin unless a protein acceptor was present in the extracellular medium. This finding suggests that the lecithin undergoing turnover was in close proximity to the extracellular medium, perhaps in the platelet membrane.
We should emphasize that the flux of fatty acids demonstrated by incubation with radioactive precursors does not necessarily indicate net synthesis or degradation of platelet lipids nor net release of free fatty acids from platelets into plasma-containing incubation media. Our data do indicate, however, the major pathways of fatty acid metabolism in the normal human platelet.

\section{ACKNOWLEDGMENTS}

Dr. Daniel Deykin is a recipient of Career Development Award 1K3-HE-25-261 from the National Heart Institute. This work was supported by grants HE-06316 and HE-10641 from the National Heart Institute, National Institutes of Health, U. S. Public Health Service.

\section{REFERENCES}

1. Marks, P. A., A. Gellhorn, and C. Kidson. 1960. Lipid synthesis in human leukocytes, platelets, and erythrocytes. J. Biol. Chem. 235: 2579.

2. Malamos, B., C. Miras, G. Levis, and J. Mantzos. 1962. The in vitro incorporation of acetate-1- $C^{14}$ into normal and leukemic leukocyte lipids. J. Lipid Res. 3: 222.

3. James, A. T., J. E. Lovelock, and J. P. W. Webb. 1959. The lipids of whole blood. I. Lipid biosynthesis in human blood in vitro. Biochem. J. 73: 106.

4. Rosenzweig, A., and P. Ways. 1966. The oxidation of long-chain fatty acids by the formed elements of human blood. Blood. 27 : 57.

5. Pittman, J. G., and D. B. Martin. 1966. Fatty acid synthesis in human erythrocytes. Evidence in mature erythrocytes for an incomplete long chain fatty acid synthesizing system. J. Clin. Invest. 4: 165.

6. Hennes, A. R., K. Awai, and K. Hammarstrand. 1964. Studies of incorporation of radioactivity into lipids by human blood. V. Pattern of fatty acid radioactivity in lipid fractions of platelets. Biochim. Biophys. Acta. 84: 610 .

7. Hennes, A. R., K. Awai, K. Hammarstrand, and G. Duboff. 1966. Carbon-14 in carboxyl carbon of fatty acids formed by platelets from normal and diabetic subjects. Nature. 210: 839.

8. Aster, R. H., and J. H. Jandl. 1964. Platelet sequestration in man. I. Methods. J. Clin. Invest. 43: 843.

9. Gaintner, J. R., D. P. Jackson, and E. W. Maynert. 1962. The action of thrombin on platelet 5-hydroxytryptamine. Bull. Johns Hopkins Hosp. 111: 185.

10. Deykin, D., C. R. Pritzker, and E. M. Scolnick. 1965. Plasma co-factors in adenosine diphosphate-induced aggregation of human platelets. Nature. 208: 296.

11. Folch, J., M. Lees, and G. H. Sloane Stanley. 1957. A simple method for the isolation and purification of total lipides from animal tissues. J. Biol. Chem. 226: 497.

12. Goldfine, H. 1966. Acylation of glycerol 3-phosphate in bacterial extracts. Stimulation by acyl carrier protein. J. Biol. Chem. 241: 3864. 
13. Freeman, C. P., and D. West. 1966. Complete separation of lipid classes on a single thin-layer plate. J. Lipid Res. 7 : 324.

14. Skipski, V. P., A. F. Smolowe, and M. Barclay. 1967. Separation of neutral glycosphingolipids and sulfatides by thin-layer chromatography. J. Lipid Res. 8: 295.

15. Archibald, F. M., and V. P. Skipski. 1966. Determination of fatty acid content and composition in ultramicro lipid samples by gas-liquid chromatography. J. Lipid Res. 7 : 442.

16. Marcus, A. J., H. L. Ullman, L. B. Safier, and H. S. Ballard. 1962., Platelet phosphatides. Their fatty acid and aldehyde composition and activity in different clotting systems. J. Clin. Invest. 41: 2198.

17. Bennett, M., and E. Coon. 1966. Inexpensive cartridge for the collection of radioactive methyl esters from gas-liquid chromatographs. J. Lipid Res. 7: 448.

18. Brady, R. O., R. M. Bradley, and E. G. Trams. 1960. Biosynthesis of fatty acids. I. Studies with enzymes obtained from liver. J. Biol. Chem. 235: 3093.

19. Miras, C. J., J. D. Mantzos, and G. M. Levis. 1965. Fatty acid synthesis in rabbit thymus preparations. Nature. 207: 1090.
20. Spector, A. A., and D. Steinberg. 1966. Release of free fatty acids from Erlich ascites tumor cells. $J$. Lipid Res. $7: 649$.

21. Marcus, A. J., and M. B. Zucker. 1965. The Physiology of Blood Platelets. Grune and Stratton, New York. 2.

22. Woodside, E. E., D. G. Therriault, and W. Kocholaty. 1964. Lipids of human platelets and their action on the blood coagulation process. Blood. 24: 76.

23. Elsbach, P. 1966. Phospholipid metabolism by phagocytic cells. I. A comparison of conversion of $\left({ }^{32} \mathrm{P}\right)$ lysolecithin to lecithin and glycerylphosphorylcholine by homogenates of rabbit polymorphonuclear leukocytes and alveolar macrophages. Biochim. Biophys. Acta. 125: 510.

24. Lands, W. E. M. 1960. Metabolism of glycerolipids. II. The enzymatic acylation of lysolecithin. J. Biol. Chem. 235: 2233.

25. Erbland, J. F., and G. V. Marinetti. 1965. The enzymatic acylation and hydrolysis of lysolecithin. Biochim. Biophys. Acta. 106: 128. 